\title{
The Impact of Anthropogenic Heat on Formation of Urban Heat Island and Energy Consumption Balance
}

\author{
P. Shahmohamadi, A. I. Che-Ani, K. N. A. Maulud, N. M. Tawil, and N. A. G. Abdullah \\ Faculty of Engineering and Built Environment, Universiti Kebangsaan Malaysia, 43600 Bangi Selangor, Malaysia \\ Correspondence should be addressed to A. I. Che-Ani, adiirfan@gmail.com
}

Received 26 December 2010; Revised 3 May 2011; Accepted 8 May 2011

Academic Editor: Andrejs Skaburskis

Copyright ( $) 2011 \mathrm{P}$. Shahmohamadi et al. This is an open access article distributed under the Creative Commons Attribution License, which permits unrestricted use, distribution, and reproduction in any medium, provided the original work is properly cited.

\begin{abstract}
This paper investigates the impact of anthropogenic heat on formation of urban heat island (UHI) and also determines which factors can directly affect energy use in the city. It explores literally the conceptual framework of confliction between anthropogenic heat and urban structure, which produced UHI intensity and affected energy consumption balance. It then discusses how these two factors can be affected and gives implication to the city and then focuses on whether actions should be taken for balancing adaptation and mitigation of UHI effects. It will be concluded by making the three important strategies to minimise the impact of UHI on energy consumption: landscaping, using albedo materials on external surfaces of buildings and urban areas, and promoting natural ventilation.
\end{abstract}

\section{Introduction}

The urban built environment itself is related to global changes in the increase of urban temperatures, the rate of energy consumption, the increased use of raw materials, pollution, and the production of waste, conversion of agricultural to developed land, loss of biodiversity, and water shortages [1]. It is clear that buildings not designed for high climatic quality use more energy for air conditioning and more electricity for lighting. Moreover, discomfort and inconvenience to the urban population due to high temperatures, wind tunnel effects in streets, and unusual wind turbulence due to the incorrect use of energy.

With the concentration of anthropogenic activities into urban areas, a climatic environmental problem, the "urban heat island" (UHI), has emerged. A UHI is a climatic phenomenon in which urban areas have higher air temperature than their rural surroundings as a result of anthropogenic modifications of land surfaces, significant energy use, and its consequent generation of waste heat. Thus, this proves to be an unsustainable factor that leads to excessive energy use for cooling and places the urban population at greater risk of increased morbidity and mortality.

According to the above perspective and considering that rapid and huge population growth is expected in the near future, it becomes increasingly important to apply UHI mitigation strategies in order to reduce energy consumption and improve the quality of life with focusing on energy consumption.

Thus, this paper investigates the anthropogenic heat factors that produce the UHI and result in the use of significantly increased use of energy. Then, according to the Oke's energy balance conceptual model, all of the energy which is absorbed by the surface through radiation or from anthropogenic heat goes somewhere and warms the air above the surface, it is evaporated away with moisture or is stored in the material as heat. For energy saving, therefore, this paper suggests some strategies to provide the best possible energy saving solution.

\section{Urban Heat Island}

The majority of cities are sources of heat and pollution, and the thermal structure of the atmosphere above them is affected by the "heat island" effect. A UHI is best visualised as a dome of stagnant warm air over the heavily built-up areas of cities [2]. The heat that is absorbed during the day by the buildings, roads, and other constructions in an urban area is re-emitted after sunset, creating high-temperature differences between urban and rural areas [3]. The exact 
form and size of this phenomenon varies in time and space as a result of meteorological, regional, and urban characteristics [4]. Therefore, UHI morphology is greatly influenced by the unique character of each city and its land uses. As seen in Figure 1, Oke [4] stated that in a larger city with a cloudless sky and light winds just after sunset, the boundary between the rural and the urban areas exhibits a steep temperature gradient to the UHI, and then the rest of the urban area appears as a "plateau" of warm air with a steady but weaker horizontal gradient of increasing temperature towards the city centre. In Figure 1, the uniformity of the "plateau" is interrupted by the influence of distinct intraurban land-uses such as parks, lakes, and open areas (cool), and commercial, industrial or dense building areas (warm).

In metropolitan areas, the urban core shows a final "peak" in the UHI where the urban maximum temperature is found. The difference between this value and the background rural temperature defines the "UHI intensity" $\left(\Delta T_{u-r}\right)$. The intensity of the UHI is mainly determined by the thermal balance of the urban region and can result in a temperature difference of up to 10 degrees [3].

The UHI phenomenon may occur during the day or during the night. Givoni [5] mentioned that the largest elevations of the urban temperatures occur during clear and still-air nights. Under these conditions, temperature elevations of about $3-5^{\circ} \mathrm{C}$ are common, but elevations of about $8-10^{\circ} \mathrm{C}$ were also observed.

Today, the majority of cities are around $2^{\circ} \mathrm{C}$ warmer than rural areas, and commercial and high-density residential areas are hotter by 5 to $7^{\circ} \mathrm{C}[6]$. There are some main parameters which influence the temperature increase in cities and play a significant role in the formation of the UHI. Therefore, UHI is caused by different factors that can be divided into two types: (1) meteorological factors, such as cloud cover, wind speed, and humidity; (2) urban structure factors, such as ventilation, surface waterproofing, thermal properties of fabric, surface geometry, and the like.

According to Landsberg [7], a UHI is present in every town and city and is the most obvious climatic manifestation of urbanisation. Clearly higher urban temperatures seriously impact the electricity demand for air conditioning in buildings and increase smog production, as well as contribute to increased emission of pollutants from power plants, including sulphur dioxide, carbon monoxide, nitrous oxides, and suspended particulates [3].

\section{Conceptual Framework: Energy Consumption Balance}

3.1. Relation between Anthropogenic Heat and Urban Structure Factors and Formation of Urban Heat Island. Urban areas are the sources of anthropogenic carbon dioxide emissions from the burning of fossil fuels for heating and cooling; from industrial processes; transportation of people and goods, and the like, [1, 8, 9]. Increases in stationary (industrial) and nonstationary (vehicles) pollutant sources result in worsening atmospheric conditions [10]. The urban environment affects many climatological parameters. Global solar radiation is seriously reduced because of increased

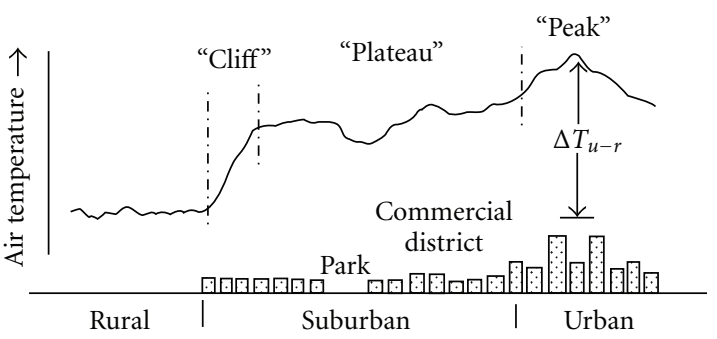

Figure 1: Generalized cross-section of a typical UHI [4].

scattering and absorption [1]. Many cities in the tropics experience weak winds and limited circulation of air which helps the accumulation of pollutants [10]. The wind speed in the canopy layer is seriously decreased compared to the undisturbed wind speed and its direction may be altered. This is mainly due to the specific roughness of a city, to channelling effects through canyons and also to UHI effects [1]. In addition, higher temperatures increase the production of secondary, photochemical pollutants, and the high humidity contributes to a hazy atmosphere.

Gartland [11] stated that although anthropogenic heat, low wind speeds, and air pollution in urban areas can contribute to UHI formation, there are two main reasons for formation of UHI:

(1) because of impermeable and watertight urban construction materials, moisture is not available to dissipate the sun's heat;

(2) dark materials in concert with canyon-like configurations of buildings and pavement collect and trap more of the sun's energy. Temperatures of dark, dry surfaces in direct sun can reach up to $88^{\circ} \mathrm{C}$ during the day while vegetated surfaces with moist soil under the same conditions might reach only $18^{\circ} \mathrm{C}$.

Rapid urbanization leads to the development of a UHI; Oke et al. $[9,12]$ grouped these causes into the following five categories, each of which represents change to the preurban environment brought about by urbanization:

(1) anthropogenic heat;

(2) air pollution;

(3) surface waterproofing;

(4) thermal properties of fabric;

(5) surface geometry.

(1) Anthropogenic heat discharge in a city also contributes to the UHI effect. Sources of anthropogenic heat include cooling and heating buildings, manufacturing, transportation, and lighting. Human and animal metabolisms are also considered sources of artificial heat [13]. Heat from these sources warm the urban atmosphere by conduction, convection, and radiation. The contribution of anthropogenic heat to the urban energy balance is largely a function of latitude and season of the year. In a temperate city, for example, anthropogenic heat flux may be a significant 
component of the energy balance in winter, yet a negligible component in summer. In a polar settlement, artificial heat flux may exceed solar heating year-round [14].

(2) Air pollution results from emissions of particulates, water vapour, and carbon dioxide from industrial, domestic, and automobile combustion processes. These atmospheric pollutants change the urban net all-wave radiation budget by (1) reducing the incident flux of short-wave (i.e., solar) radiation, (2) re-emitting long-wave (i.e., infrared) radiation from the urban surface downward to where it is retained by the ground, and (3) absorbing long-wave radiation from the urban surface, effectively warming the ambient air [4]. Lee [14] estimated that urban-rural differences in downward long-wave radiation flux may be of the order of 10 percent, depending on the city population and the presence of heavy industry.

(3) Surface waterproofing refers to the predominance of impermeable surface in urban areas. Buildings and paved streets quickly shed precipitation into catchment basins, creating an evaporation deficit in the city. Conversely, in rural areas exposed soils and natural vegetation retain water for evaporative cooling. A dry urban surface cover enhances sensible heat transfer and suppresses latent heat flux whereas moist rural surface suppress sensible heat transfer and enhance latent heat flux.

(4) The fourth factor contributing to the formation of UHIs relates to the thermal properties of the urban fabric. The heat capacity, and consequently thermal inertia, of urban construction materials such as concrete and asphalt is greater than that of natural materials found in rural environments. A greater heat capacity means that urban materials absorb and retain more solar radiation than do rural soils and vegetation. Reflection of short-wave solar radiation is also affected by the properties of the urban fabric. Urban albedos are, on average, 5-10 percent lower than rural values [14]. This contributes to the greater diurnal absorption of short-wave radiation in urban areas.

(5) The complex geometry of urban surfaces influences air temperatures in two ways. First, increased friction created by a rough urban surface (as compared to a smooth rural surface) reduces horizontal airflow in the city. Mean annual wind speeds within cities are approximately 30-40 percent lower than mean annual wind speeds in the countryside [14]. Warm air stagnates in the urban canyons unless ventilated by cool rural air. Lower wind speeds in the city also inhibit evaporative cooling. And second, the complex geometry of the urban surface changes the urban radiation budget. During the day, vertical canyon walls trap (i.e., reflect and absorb) short-wave radiation. Night-time losses of infrared energy are also retarded due to the decreased sky view factor below roof level. Rural surfaces, on the other hand, are comparatively smooth and therefore experience greater nocturnal radiative flux divergence than a complex urban surface.

Anthropogenic heat is generated by human activity and comes from many sources, such as buildings, industrial processes, cars, and even people themselves [11]. Urban centres (commercial centres) tend to have higher energy demands than surrounding areas as a result of higher production of anthropogenic heat. Though the UHI effect reduces the
TABLE 1: Urban and suburban characteristics important to UHI formation and their effect on the energy balance of the earth's surface [11].

\begin{tabular}{ll}
\hline $\begin{array}{l}\text { Characteristic contributing to } \\
\text { UHI formation }\end{array}$ & Effect on the energy balance \\
\hline $\begin{array}{l}\text { Lack of vegetation } \\
\text { Widespread use of } \\
\text { impermeable surfaces }\end{array}$ & Reduced evaporation \\
$\begin{array}{l}\text { Increased thermal diffusivity of } \\
\text { urban materials }\end{array}$ & Increased heat storage \\
$\begin{array}{l}\text { Low solar reflectance of urban } \\
\text { materials }\end{array}$ & Increased net radiation \\
$\begin{array}{l}\text { Urban geometries that trap heat } \\
\text { Urban geometries that slow }\end{array}$ & Increased net radiation \\
wind speeds & Reduced convection \\
$\begin{array}{l}\text { Increased levels of air pollution } \\
\text { Increased energy use }\end{array}$ & Increased net radiation \\
\hline
\end{tabular}

need for heating in the winter, this is outweighed by the increased demand for air-conditioning during the summer months [7], which in turn causes increased local and regional air pollution through fossil-fuel burning electric power generation. The pollution created by emissions from power generation increases absorption of radiation in the boundary layer [15] and contributes to the creation of inversion layers. Inversion layers prevent rising air from cooling at the normal rate and slow the dispersion of pollutants produced in urban areas [16]. To determine how much anthropogenic heat is produced in any region, all energy use (commercial, residential, industrial, and transportation) must be estimated. The sum is then divided by the region's area to enable comparisons of different cities to be made [11].

In developed countries where concerted action is being taken on UHIs, the main concern is on the large increase in power consumption in urban areas to cool down buildings, with additional air-conditioners or a heavier usage of existing air-conditioners. Higher air temperatures also mean that the air quality deteriorates as a result of increased ozone and pollution.

3.2. Energy Consumption Balance. As discussed previously, there is no single cause of the UHI. In fact, many factors combine to warm cities. Gartland [11] listed urban characteristics contributing to UHI formation in Table 1 . These characteristics can be grouped into five main causes of UHI formation:

(1) increased anthropogenic heat;

(2) reduced evaporation;

(3) increased heat storage;

(4) increased net radiation;

(5) reduced convection.

The anthropogenic heat interacts with its environment in a complex manner. To understand and simplify the complexity, Oke [17] has suggested an equation called the "energy balance" in which the heat generated by and 
contained in an area could be calculated by this equation:

$$
Q^{*}+Q_{F}=Q_{H}+Q_{E}+\Delta Q_{S}+\Delta Q_{A},
$$

where, $Q^{*}$ : the net all-wave radiation, $Q_{F}$ : the anthropogenic heat, $Q_{E}$ : the turbulent latent heat flux, $Q_{H}$ : the turbulent sensible heat flux, $\Delta Q_{S}$ : the sensible heat storage, $\Delta Q_{A}$ : the net heat advection.

Net Radiation ( $\left.Q^{*}\right)$. As shown below, net radiation encompasses four separate radiation process taking place at the Earth's surface [11]:

$$
\begin{aligned}
\text { Net radiation }= & \text { Incoming solar }- \text { Reflected solar } \\
& + \text { Atmospheric radiation } \\
& - \text { surface radiation, }
\end{aligned}
$$

where, Incoming solar: the amount of energy radiating from the sun, Reflected solar: the amount of solar energy that bounces off a surface, based on the solar reflectance of the material, Atmospheric radiation: heat emitted by particles in the atmosphere, such as water vapour droplets, clouds, pollution, and dust, and Surface radiation: heat radiated from a surface itself.

The net all-wave radiation could then be calculated as the difference between the incoming and outgoing parts $[18,19]$. The incoming short wave solar radiation was reported to be attenuated due to the heavy smoke over urban areas, $[17,20]$. The attenuation has been reported to be as high as $33 \%$ in some cases [21] and has also been reported as a cause of urban cool island [20]. In some other areas, on the other hand, the attenuation has not been observed [19]. It is reported that the attenuation of incoming short-wave radiation is compensated by albedo-related drop in outgoing shortwave radiation and enhancement of incoming longwave radiation is compensated by an increase in outgoing long-wave radiation due to the high surface temperature emittance. It was reported that most of the attenuated part is diffused and received back and the net difference between the urban and rural areas may not be more than $5 \%,[15,17]$.

Anthropogenic Heat $\left(Q_{F}\right)$. Anthropogenic heat represents the heat generated from stationary and mobile sources of an area. It is reported that the $Q_{F}$ must either be converted to radiations, sensible heat flux, or latent heat flux, or it is stored [19]. This component has been modelled as the sum of heat generated by the buildings, vehicles, and people, $[22,23]$ or as the residual of other terms [19].

Oke [17] reported that anthropogenic heat release could be related to the population and its per capita energy use. Taha [24] reported that the anthropogenic heat has smaller effect than albedo and vegetation cover, and that it is negligible in commercial and residential areas. Offerle et al. [25], on the other hand, have considered it a significant input in winter. It seems that depending on the area and its energy use the term could be significant or negligible and it could have varying diurnal, seasonal, or even weekly trends.
Turbulent Heat Fluxes $\left(Q_{E}, Q_{H}\right)$. Turbulent heat fluxes are comprised of the sensible and latent heat fluxes. These can be directly derived from eddy correlation, or measured using appropriate equipments. The heavily built urban areas are reported to be responsible for increased sensible heat flux which is reported to vary as per the built surface [17]. The intensity of latent heat flux, on the other hand, varies from situation to situation as concluded by Hafner and Kidder [26]. Grimmond [23] described the latent heat flux as the largest portion in the surface energy balance (SEB) while Masson [27] has neglected it in his proposed town energy balance scheme. Although it is likely that the latent heat flux will be low in an urbanized area due to decreased vegetation, it could be high in vegetated parts of the city. The study conducted by Suckling [28] reported a Bowen ratio, sensibleheat-flux-to-latent-heat-flux ratio, of up to $98 \%$ for a suburban lawn. It was reported that the turbulent heat fluxes vary with respect to the $Q^{*}[25,29]$. Thermal admittance and ground moisture availability are reported to be other important factors in quantifying the turbulent heat fluxes [17].

Storage Heat Flux $\left(\Delta Q_{S}\right)$. Christen and Vogt [19] reported that due to the complicated configuration of surface materials, orientations, and their interactions, the direct measurement of storage heat flux in an urbanized area is almost impossible. The term is, therefore, usually modelled or determined as the residual of the SEB equation. It is reported that an increase in the net all-wave radiation directly increases the stored heat flux. Grimmond [23] found an increase of around $60 \%$ in the monthly averaged day-time ratio of stored heat flux to the net all-wave radiation with an increase of net all-wave radiation.

Net Heat Advection $\left(\Delta Q_{A}\right)$. Net heat advection could be referred to as the inaccurate measurement due to spatial gradient in temperature, humidity, and wind. It is suggested that the effects of advection could be negligible provided that caution has been taken in deciding the measurement height [19].

The preceding discussion highlights how energy is transformed to and from the Earth's surface. The energy balance equation is based on the first law of thermodynamics, which states that energy is never lost. For a surface on the Earth, this means that all of the energy absorbed by the surface through radiation or from anthropogenic heat goes somewhere. Either it warms the air above the surface, is evaporated away with moisture, or is stored in the material as heat.

Other statistical data show that the amount of energy consumed by cities for heating and cooling offices and residential buildings has increased significantly in the last two decades. Emmanuel [30] has shown the rate of energy consumption of three countries, US, UK, and Sri Lanka (in Table 2). A comparison of energy-use patterns between a developed country like the US and a developing country like Sri Lanka shows that transportation and activities within buildings consume a considerable share of energy in both cases.

Increased anthropogenic heat has a direct effect on building energy consumption that an increase in the production of anthropogenic heat leads to raise the electricity demand 


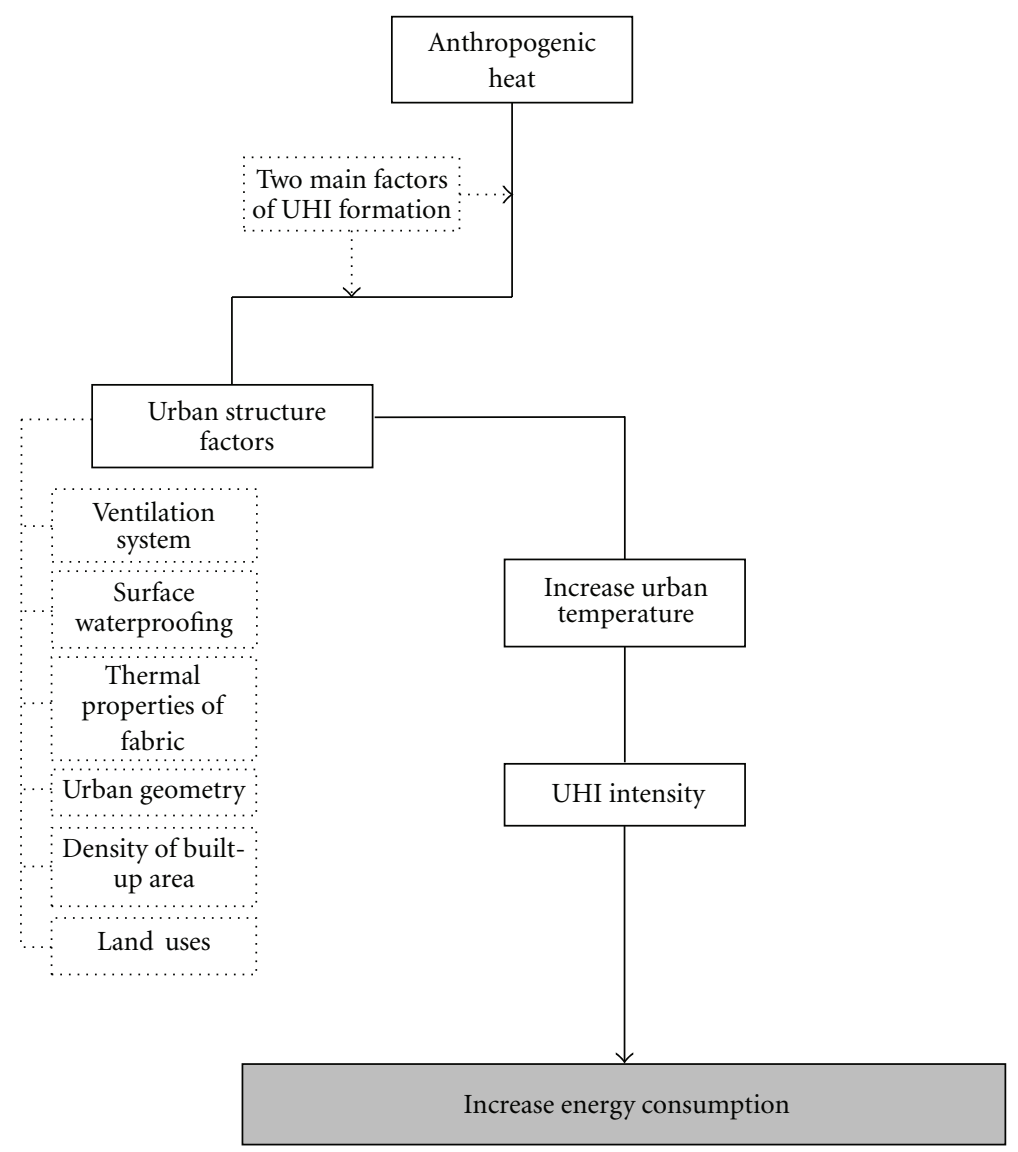

FIGURE 2: The process of increasing energy consumption.

TABle 2: Patterns of commercial energy consumption [30].

\begin{tabular}{|c|c|c|c|}
\hline \multirow{2}{*}{ Activity } & \multicolumn{3}{|c|}{ Energy consumption ( $\%$ of total country needs) } \\
\hline & US & U.K. & Sri Lanka \\
\hline Industry & 41.2 & 32.0 & 9.9 \\
\hline Transportation & 21.0 & 18.0 & 16.4 \\
\hline $\begin{array}{l}\text { Building energy } \\
\text { needs }\end{array}$ & 28.0 & 48.0 & 67.0 \\
\hline Agriculture/other & 7.7 & 2.0 & 6.7 \\
\hline
\end{tabular}

for cooling and the production of carbon dioxide and other pollutants.

Therefore, it can be concluded that increasing the production of anthropogenic heat, which leads to raised temperatures and generates a UHI that provides a warm air canopy over the city. Consequently, it causes significantly increased energy consumption to heat and cool buildings. This process is summarised in Figure 2.

This paper has tried to develop a concept to show the conflict between anthropogenic heat and urban structure factors can affect the energy balance.

This paper highlights energy consumption, anthropogenic heat, and urban structure factors as the key components; according to Bridgman et al. [31], replacing grass, soil, and trees with asphalt, concrete, and glass; the rounded, soft shapes of trees and bushes with blocky, angular buildings and towers; artificial heat from buildings, air conditioners, industry, and automobiles; efficiently disposing of precipitation in drains, sewers, and gutters, preventing surface infiltration; emitting contaminants from a wide range of sources, which with resultant chemical reactions can create an unpleasant urban atmosphere, higher production of anthropogenic heat, and an increased UHI intensity.

Compiling the three key components into a concept is meaningful in reducing UHI effects and achieving energy consumption balance. The relationship between the three key components is presented in the conceptual model shown in Figures 3 and 4.

In Figure 3, the shaded area represents the UHI intensity. A greater conflict between anthropogenic heat and urban structure factors causes higher UHI intensity. With increasing UHI intensity, energy consumption becomes imbalanced while Figure 4 shows that by mitigating UHI effects, energy consumption balance can be achieved.

This process can be described in the following way:

$$
\begin{gathered}
\mathrm{UHI} \downarrow=\mathrm{ECB}, \\
\mathrm{UHI} \downarrow=\mathrm{AH} \downarrow+\mathrm{USF} \downarrow, \\
\mathrm{AH} \downarrow+\mathrm{USF} \downarrow=\mathrm{ECB},
\end{gathered}
$$




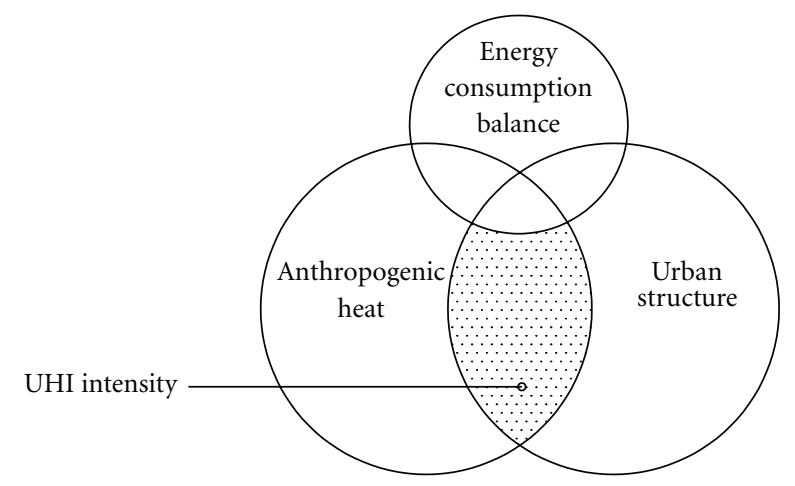

FIgURe 3: Conflict between anthropogenic heat and urban structure factors, creation of UHI, and its effect on energy consumption balance.

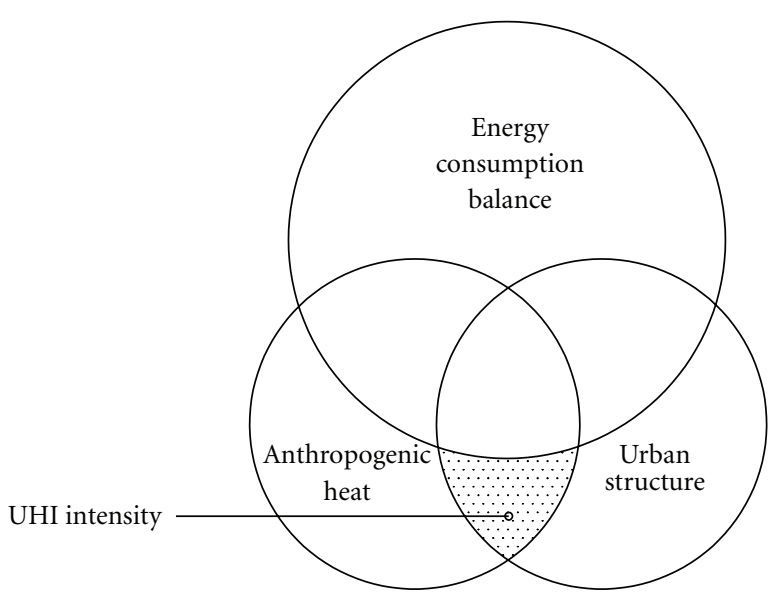

FIGURE 4: Mitigation of UHI has direct effect on energy consumption balance.

where, UHI is the urban heat island ( $\downarrow$ decrease), ECB is the energy consumption balance, $\mathrm{AH}$ is the anthropogenic heat, USF is urban structure factors.

Therefore, by decreasing anthropogenic heat and urban structure factors, mitigation of UHI effects is achievable.

Although decreasing the anthropogenic heat is dependent on urban structure factors, an optimal and realistic solution is to focus on urban structure factors, such as natural ventilation, surface materials and landscape, or vegetation covers to decrease UHI intensity and create energy consumption balance;

$$
\begin{gathered}
\mathrm{ECB}=\mathrm{MEC}+\mathrm{LEC}+\mathrm{NVEC}, \\
\mathrm{MEC}=\mathrm{LEC}=\mathrm{NVEC},
\end{gathered}
$$

where, MEC is the amount of reflectivity and emissivity of surface materials, LEC is the amount of appropriate landscape or vegetation covers; NVEC is the appropriate amount of wind introduced into a built environment; an appropriate solution is adequate vegetation, natural ventilation, and high albedo materials, which results in an acceptable impact on energy consumption balance.

Under such circumstances, a balanced urban environment can be created (Figure 5). This means that adding natural ventilation, vegetation covers, and high-albedo and high-emissivity materials in buildings can reduce UHI effects and balance energy consumption. This will be described in the next section.

\section{Mitigation of Urban Heat Island Effects: Achieving Energy Consumption Balance}

The reduction of the energy consumption of buildings by combining techniques to improve the thermal quality of the ambient urban environment with the use of up-to-date alternative passive heating, cooling, and lighting techniques can partly decrease these kinds of environmental problems.

Asimakopoulos et al. [3] stated that some of the factors that usually have a negative effect on the low energy consumption include the design and construction of urban buildings.

(a) The layout of the basic road network with a specific orientation. This layout affects the buildings on either side of the road, giving them an orientation that, in most cases, is not suitable for implementing solar and energy saving techniques.

(b) The relationship between the height of a building and the width of the road, which causes overshadowing and thus prevents access to direct sunlight in living spaces.

(c) The relationship between plot frontage and depth, which can determine how many internal spaces will have a southern aspect.

(d) Densely built urban centres, which result in the obstruction of airflow and sunlight by the walls of tall buildings.

(e) A lack of greenery that has been replaced by concrete and tarmac.

(f) Overshadowing caused by adjacent buildings and other landscape features, which is difficult to avoid.

(g) Building regulations and codes that in most cases determine the dimensions of a building and thus its geometrical form and its position on the plot.

It also must be noted that higher temperature and less intensive winds are causes of UHI effects. In addition, inappropriate orientation, high density, and shading can directly affect UHI formation. If proper interventions are implemented in urban design, better climate conditions will be achieved when serious overheating problems occur. A large number of air-conditioning appliances leads to increased cooling loads during the summer and to overconsumption of electric energy, which also increase peak energy demand and creates failures in the energy transport network. Energy saving techniques that can be applied in a 


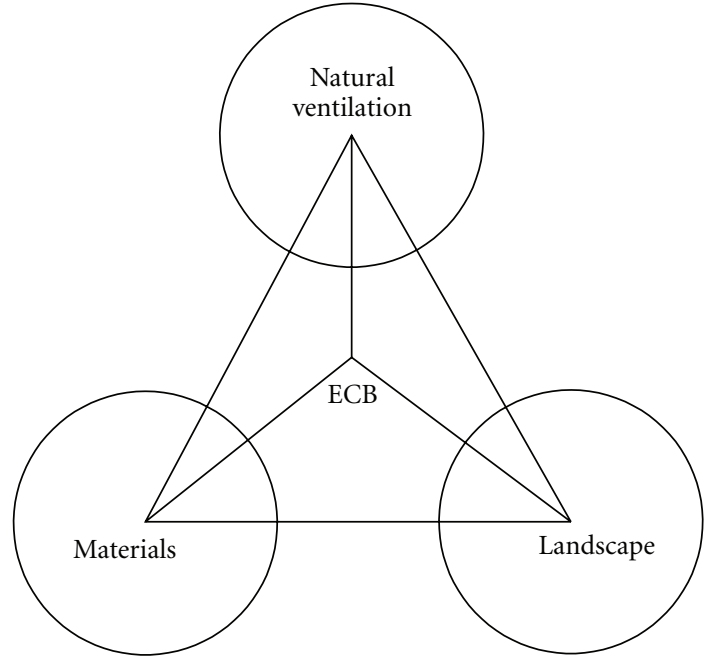

FIGURE 5: Achieve energy consumption balance by providing balance with natural ventilation, high-albedo materials, and vegetation covers.

building includes two kinds of strategies that can be divided into urban elements (macro scale) and building elements (micro scale) strategies. The first strategy includes the energy conservation methods, which involve application of some strategies in urban areas, while the second method includes strategies for buildings. This paper focuses on three main strategies in each scale.

The combination of these two categories will provide the best possible energy saving solution. According to the above considerations these strategies are described in the following sections.

4.1. Promoting Natural Ventilation. Natural ventilation is the most effective passive cooling technique that can provide cooling during both day and night, while night ventilation is a very effective strategy in hot climates [3]. Some strategies for buildings can provide natural ventilation and save energy. Therefore, this paper recommends some strategies to achieve this aim.

(1) Natural ventilation by arranging the openings in buildings to face the prevailing wind can provide efficient natural ventilation and create a healthy indoor air quality.

(2) Natural ventilation by ventilated roofs eliminates overheating.

(3) Variation in building height can create better wind at higher levels if differences in building heights between rows are significant.

(4) Building orientation with adequate gaps is useful for good airflow.

(5) Increasing building permeability by providing void decks or pilots at ground level or at midspan.
4.2. Using Appropriate Materials on External Surfaces of the Buildings. An increase in the surface albedo has a direct impact on the energy balance of a building. Cities and urban areas in general are characterised by a relatively reduced effective albedo as a result of two mechanisms [1].

(1) Darker buildings and urban surfaces absorb solar radiation.

(2) Multiple reflections inside urban canyons significantly reduce the effective albedo.

As Asimakopoulos et al. [3] stated, numerous studies have been performed to evaluate the direct effects of albedo change and demonstrate the benefits of using reflective surfaces. In all cases, the roof temperatures are significantly reduced, but the degree to which the cooling load decreases depends on the structure of the roof and on the overall thermal balance of the building. Surface materials with a high albedo index to solar radiation reduce the amount of energy absorbed through building envelopes and urban structures, and keep the surface cooler. Building materials can be divided into pavement materials, roof materials, and building envelopes.

Therefore, this paper recommends using reflective materials on external surface of building to reduce UHI effects and improve the urban environment.

4.2.1. Using High-Albedo Materials on Building Surfaces. A material with high albedo can reduce the solar heat gain during the daytime. The surface temperature of the material is lower than that of a material with low albedo. Because the urban ambient temperature is associated with the surface temperatures of the building façade, lower surface temperature can obviously decrease the ambient air temperature and eventually contribute to better urban thermal environment.

4.2.2. Using White Pavement Instead of Asphalt. Asphalt temperature can reach $63^{\circ} \mathrm{C}$ and white pavements only reach $45^{\circ} \mathrm{C}$ [1]. Lower surface temperatures contribute to decreasing the temperature of the ambient air because the heat convection intensity from a cooler surface is lower. Such temperature reductions have a significant impact on cooling energy consumption in urban areas.

4.2.3. Using Cool Roofs. Cool roofs reduce building heatgain, create saving air conditioning expenditures, enhance the life expectancy of both the roof membrane and the building's cooling equipment, improve thermal efficiency of the roof insulation, reduce the demand for electric power, reduce resulting air pollution and greenhouse gas emissions, provide energy savings, and mitigate UHI effects.

4.3. Providing Appropriate Landscape. Providing an appropriate landscape in building can also contribute to energy consumption reduction. The impact of an appropriate landscape around a building on energy consumption and surrounding temperature regime is very important. Landscaping the surrounding area is a basic criterion to improving the 
external climatic conditions. As mentioned by Asimakopoulos et al. [3], shading from trees can do the following.

(1) Significantly decrease the energy required for cooling.

(2) Decrease the rate of heat convection inside buildings because of shaded surfaces that have a lower temperature.

(3) Decrease the radiation exchange of the wall with the sky.

Sailor [32] considers that the low evaporative heat flux in cities is the most significant factor in the development of a UHI. When vegetation is placed on urban surfaces, thermal balances can shift to new conditions that are closer to the cooler conditions of rural areas. It is estimated that $1460 \mathrm{~kg}$ of water is evaporated from an average tree during a sunny day, which consumes about $860 \mathrm{MJ}$ of energy; this offers a cooling effect outside a building that is equal to five average air conditioners [1]. Furthermore, to reduce energy consumption, various types of trees and vegetation covers in different parts of the buildings must be considered.

Therefore, this paper recommends using green spaces in vertical and horizontal layers.

4.3.1. Vertical Green Spaces. Green spaces in some parts of buildings that provide natural ventilation or appropriate landscapes in different layers or floors of buildings with a multiuse function can significantly decrease the energy required to cool buildings.

4.3.2. Horizontal Green Spaces. Green spaces on roofs absorb heat, decrease the tendency towards thermal air movement, and filter air movement. Through the daily dew and evaporation cycle, plants on vertical and horizontal surfaces are able to cool cities. In the process of evapotranspiration, plants use heat energy from their surroundings when evaporating water.

\section{Conclusions}

There is strong scientific evidence that the average temperature of the earth's surface is rising because of increased energy consumption. Global warming has a major impact on human life and the built environment. Therefore, an effort must be made to reduce energy use and to promote green energies, particularly in the building sector. Energy balance can be achieved by minimising energy demand, rational energy use, recovering heat, and using more green energies. This paper was a step towards achieving that goal. The adoption of green or sustainable approaches to the way in which society is run is seen as an important strategy in finding a solution to the energy problem. As discussed in this paper, one of the most important factors that increases energy use is the formation of urban heat islands. Therefore, this paper considers the effects of UHI and by recognising them, proposes beneficial solutions that can lead to energy consumption balance.

\section{References}

[1] M. Santamouris, Energy and Climate in the Urban Built Environment, James \& James, London, UK, 2001.
[2] M. R. Emmanuel, An Urban Approach to Climate-Sensitive Design; Strategies for the Tropics, Spon Press, London, UK, 2005.

[3] D. N. Asimakopoulos, V. D. Assimakopoulos, N. Chrisomallidou et al., Energy and Climate in the Urban Built Environment, James \& James, London, UK, 2001.

[4] T. R. Oke, Boundary Layer Climates, Methuen and Co., New York, NY, USA, 2nd edition, 1987.

[5] B. Givoni, Climate Considerations in Building and Urban Design, John Wiley \& Sons, Canada, 1998.

[6] G. Bonan, Ecological Climatology, Cambridge University Press, 2002.

[7] H. E. Landsberg, The Urban Climate, Academic Press, Md, USA, 1981.

[8] S. Grimmond, "Urbanization and global environmental change: local effects of urban warming," Geographical Journal, vol. 173, no. 1, pp. 83-88, 2007.

[9] T. R. Oke, "Canyon geometry and the nocturnal urban heat island: comparison of scale model and field observations," Journal of Climatology, vol. 1, no. 3, pp. 237-254, 1981.

[10] M. Roth, "Effects of cities on local climates," in Proceedings of the Workshop of IGES/APN Mega-City Project, Kitakyushu, Japan, January 2002.

[11] L. Gartland, Heat Islands: Understanding and Mitigating Heat in Urban Areas, Earthscan Press, London, UK, 2008.

[12] T. R. Oke, G. T. Johnson, D. G. Steyn, and I. D. Watson, "Simulation of surface urban heat islands under "ideal" conditions at night—part 2: diagnosis of causation," BoundaryLayer Meteorology, vol. 56, no. 4, pp. 339-358, 1991.

[13] J. T. Peterson, "The climate of cities: a survey of recent literature," in Climate in Review, G. McBoyle, Ed., pp. 264-285, 1973.

[14] D. O. Lee, "Urban climates," Progress in Physical Geography, vol. 8 , no. 1 , pp. 1-31, 1984

[15] T. R. Oke, "The energetic basis of the urban heat island (Symons Memorial Lecture, 20 May 1980)," Quarterly Journal, Royal Meteorological Society, vol. 108, no. 455, pp. 1-24, 1982.

[16] K. Sahashi, T. Hieda, and E. Yamashita, "Nitrogen-oxide layer over the urban heat island in Okayama city," Atmospheric Environment, vol. 30, no. 3, pp. 531-535, 1996.

[17] T. R. Oke, "The urban energy balance," Progress in Physical Geography, vol. 12, no. 4, pp. 471-508, 1988.

[18] J. A. Brotzge and K. C. Crawford, "Examination of the surface energy budget: a comparison of eddy correlation and bowen ratio measurement systems," Journal of Hydrometeorology, vol. 4, no. 2, pp. 160-178, 2003.

[19] A. Christen and R. Vogt, "Energy and radiation balance of a central European City," International Journal of Climatology, vol. 24, no. 11, pp. 1395-1421, 2004.

[20] J. Sang, H. Liu, H. Liu, and Z. Zhang, "Observational and numerical studies of wintertime urban boundary layer," Journal of Wind Engineering and Industrial Aerodynamics, vol. 87, no. 2-3, pp. 243-258, 2000.

[21] G. Stanhill and J. D. Kalma, "Solar dimming and urban heating at Hong Kong," International Journal of Climatology, vol. 15, no. 8, pp. 933-941, 1995.

[22] D. J. Sailor and L. Lu, "A top-down methodology for developing diurnal and seasonal anthropogenic heating profiles for urban areas," Atmospheric Environment, vol. 38, no. 17, pp. 2737-2748, 2004.

[23] C. S. B. Grimmond, “The suburban energy balance: methodological considerations and results for a mid-latitude west coast city under winter and spring conditions," International Journal of Climatology, vol. 12, no. 5, pp. 481-497, 1992. 
[24] H. Taha, "Urban climates and heat islands: albedo, evapotranspiration, and anthropogenic heat," Energy and Buildings, vol. 25, no. 2, pp. 99-103, 1997.

[25] B. Offerle, C. S. B. Grimmond, K. Fortuniak, K. Kłysik, and T. R. Oke, "Temporal variations in heat fluxes over a central European city centre," Theoretical and Applied Climatology, vol. 84, no. 1-3, pp. 103-115, 2006.

[26] J. Hafner and S. Q. Kidder, "Urban heat island modeling in conjunction with satellite-derived surface/soil parameters," Journal of Applied Meteorology, vol. 38, no. 4, pp. 448-465, 1999.

[27] V. Masson, "A physically-based scheme for the urban energy budget in atmospheric models," Boundary-Layer Meteorology, vol. 94, no. 3, pp. 357-397, 2000.

[28] P. W. Suckling, "The energy balance microclimate of a suburban lawn," Journal of Applied Meteorology, vol. 19, no. 5, pp. 606-608, 1980.

[29] A. J. Arnfield and C. S. B. Grimmond, "An urban canyon energy budget model and its application to urban storage heat flux modeling," Energy and Buildings, vol. 27, no. 1, pp. 61-68, 1998.

[30] R. Emmanuel, "Energy Conscious Urban Design Guidelines for Warm Humid Cities: Strategies for Colombo, Sri Lanka," Journal of Architectural \& Planning Research, vol. 12, no. 1, pp. 58-75, 1995.

[31] H. Bridgman, R. Warner, and J. Dodson, Urban Biophysical Environments, Oxford University Press, New York, NY, USA, 1995.

[32] D. J. Sailor, "Sensitivity of coastal meteorology and air quality to urban surface characteristics," in Proceedings of the 8th Joint Conference on the Applications of Air Pollution Meteorology, vol. 8, pp. 286-293, American Meteorological Society, Boston, Mass, USA, 1994. 


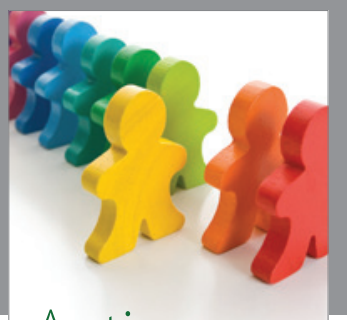

Autism

Research and Treatment
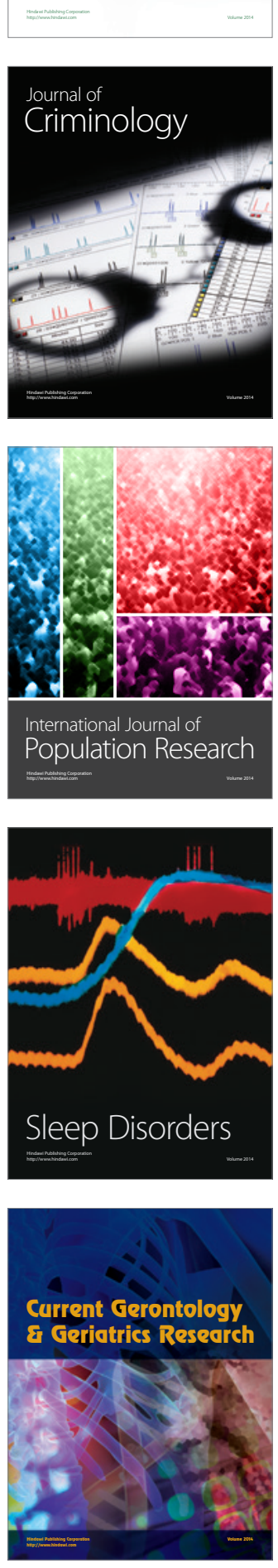
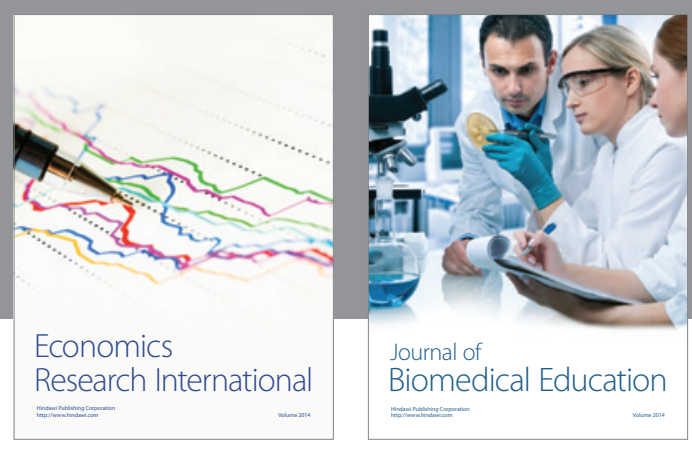

Journal of

Biomedical Education

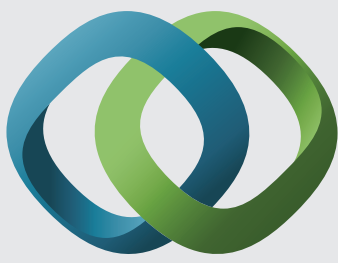

\section{Hindawi}

Submit your manuscripts at

http://www.hindawi.com
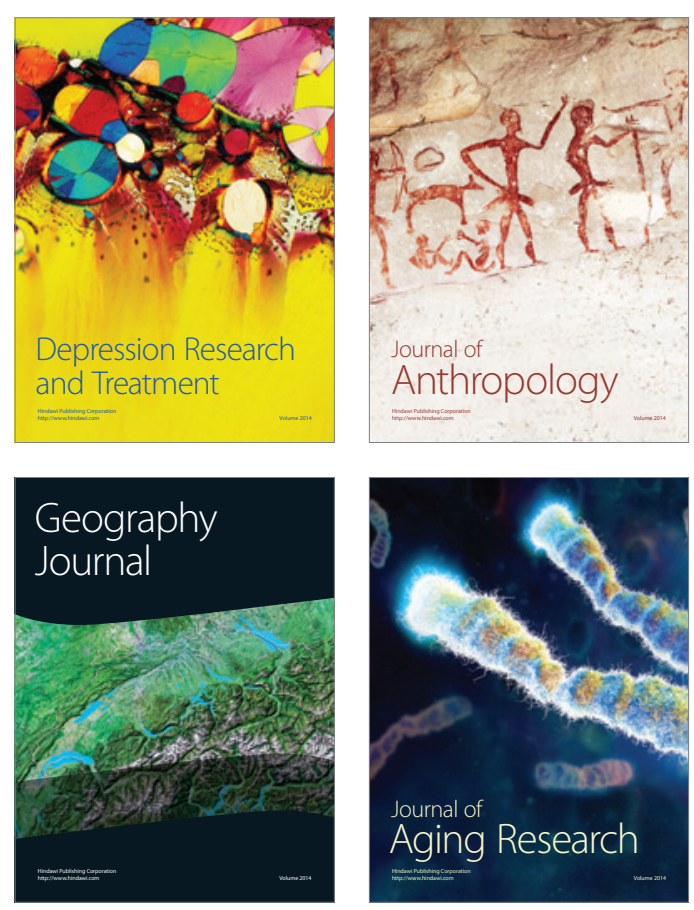

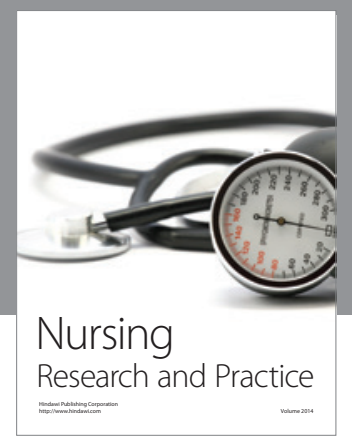

Nursing

Research and Practice

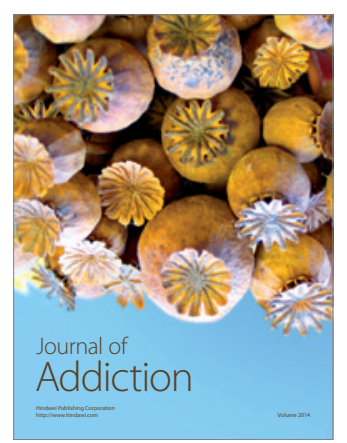

Child Development

Research

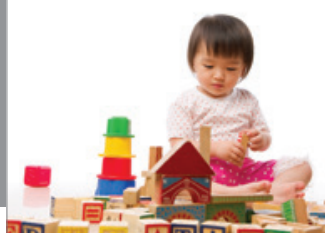

迥
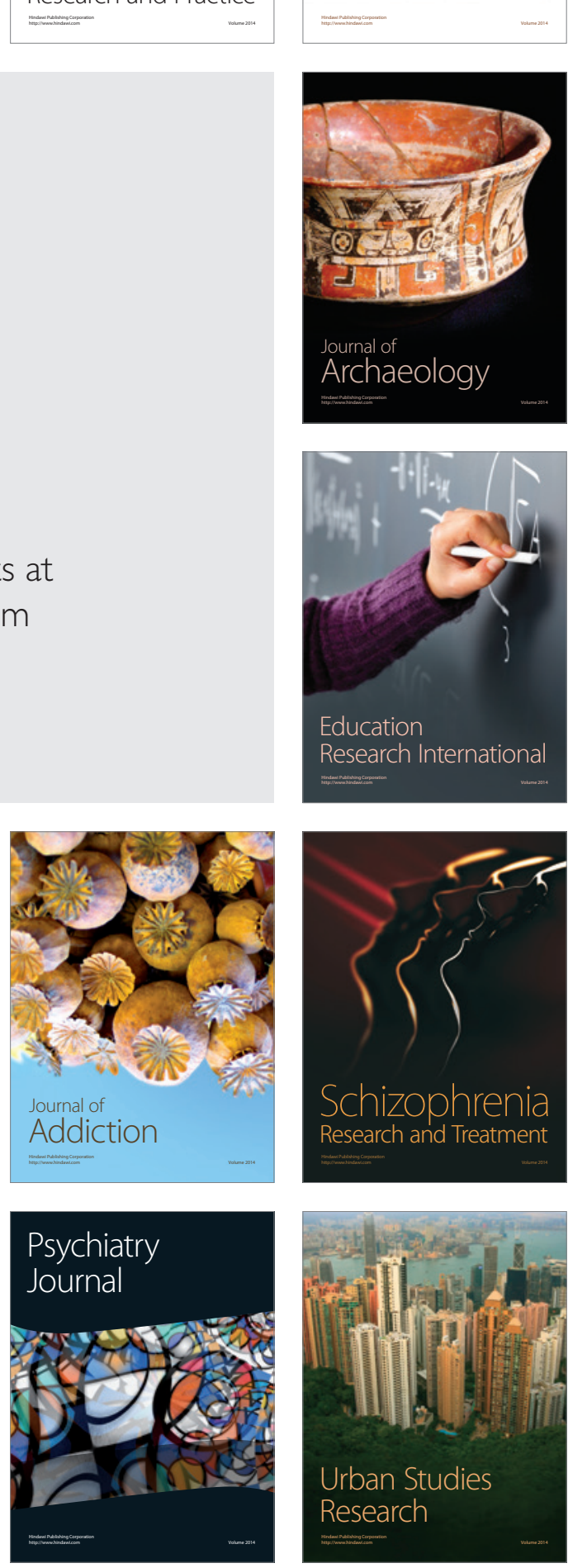